\section{Epidural fentanyl does not influence intravenous PCA requirements in the post-Caesarean patient}

Ferne B. Sevarino MD, ${ }^{*}$ Claude McFarlane MD, $\dagger$ Raynond S. Sinatra MD PhD*
Forty ASA physical stanus I or II patients scheduled for elective Caesarean delivery were studied to determine the effect of epidural fentanyl on post-Caesarean delivery analgesic requirements as administered by intravenous patien-controlled amalgesia (PCA). Following delivery of the infant, under epidural anaesthesia with lidlocaine $2 \%$ with 11200,000 epinephrine, patients were randomly assigned to receive either $10 \mathrm{ml}$ of preservative-free normal saline via the' epidural calheter or 100 $\mu \mathrm{g}$ of fentanyl with $8 \mathrm{ml}$ preservative-free normal saline in a double-blinded fashion. On arrival in the post-anesthesia recovery room (PAR), patients were provided with intravenous PCA meperidine $12.5 \mathrm{mg}$ every eight minures as needed. Patients were visited at intervals over the next $24 \mathrm{hr}$ to determine if any differences in narcolic requirements, demands for narcotics, or severity of pain were noted. No differences were observed in any values between the groups. II is concluded that a single bolus of epidural fentanyl does not provide an advantage for postoperative pain relief in this patient population.

Quarante patientes ASA l et II c'édulées pour une césarienne furent étudiées afin de déterminer l'effet de l'épidurale au fentanyl sur le besoin d'analgésie postopératoire avec la rechnique de PCA. Après l'accouchement de l'enfant sous

\section{Key words}

ANAESTHESIA: obstetrical;

ANALGESIA: epidural, postoperative;

LOCAL ANAESTHETICS: lidocaine;

OPIOIDS: fentanyl.

From the Department of Anesthesiology, Yale University School of Medicine, 333 Cedar Street, New Haven, CT 06510.

Address correspondence 1o: Dr. F. Sevarino, Department of Anesthesiology, Yale University School of Medicine, 333 Cedar Street, Box 3333, New Haven, CT 06510.

Presented in part at the annual meeting of the American Society of Anesthesiologists in New Orleans, LA, October 1989.

Accepted for publication 14th January, 1991. anesthésie épidurale avec la lidocaïne 2\% el 1/200,000 d'épinéphrine, les patientes furent randomisées afin de recevoir soil $10 \mathrm{ml}$ de soluté physiologique sans préservatif à travers le cathéter épidural ou $100 \mu \mathrm{g}$ de Jentanvl avec $8 \mathrm{ml}$ de soluté physiologique sans préservarif d' une faģon doublemem i l' insu. A l'arrivée en salle de réveil, on a mis à leur disposition la PCA intraveineuse avec la mépéridine $12,5 \mathrm{mg}$ chaque huit minutes au besoin. Les patientes furent visitees par intervalle pour las prochaines 24 heures afin de dérerminer s'il y avait des différences dans la demande pour narcotique, el on a noté aussi la sévérité de la douleur. Aucune différence ne ful observée dans aucune des valeurs entre les groupes. On conclut qu' im bolus unique de fentanyl par voie épidurale ne fournit aucun avanage dans le soulagement de la douleur postopératoire dans celle population de patientes.

Fentanyl, a potent lipophilic opioid, provides effective epidural analgesia following Caesarean delivery ${ }^{1,2}$ and general surgery. ${ }^{3,4}$ High-lipid solubility confers clinical advantages over morphine, including rapid onset of analgesia and reduced potential for delayed respiratory depression. ${ }^{5,6}$ Rapid decrease in CSF fentanyl concentrations due to uptake and, to a lesser degree, elimination, limits the duration of analgesia produced by epidural fentanyl.

At our institution over $90 \%$ of patients recovering from Caesarean delivery performed under epidural anaesthesia elect to receive iv PCA. In this setting the reliability, rapid onset, and limited duration of epidural fentanyl analgesia appear to smooth the transition from resolution of local anaesthetic blockade until effective pain relief is noted with PCA. The following double-blind investigation which permitted patients to initiate and to self-administer narcotics postoperatively via a PCA system was designed to measure the duration of postoperative analgesia and assess the overall benefit of epidurally administered fentanyl in patients following Caesarean delivery performed under epidural anaesthesia using $2 \%$ lidocaine. 


\section{Methods}

The protocol was approved by the Human Investigation Committee of Yale University School of Medicine, and written informed consent was obtained from each patient before entry into the study. Forty ASA physical status I or II patients scheduled for eleclive Caesarean delivery were enrolled into the study. Before initiation of anaesthesia, patients were instructed in the use of PCA and were prehydrated with $1500 \mathrm{ml}$ of lactated Ringer's solution. An epidural catheter was inserted at the third lumbar interspace and anaesthesia to the third or fourth thoracic dermatome was achieved using carbonated $2 \%$ lidocaine with 1:200,000 epinephrine. The patients were positioned supine with a right hip roll to produce a pelvic tilt of approximately $15^{\circ}$ to the left.

After delivery of the baby, 40 patients were randomly assigned to receive either $10 \mathrm{ml}$ of preservative-free normal saline or $100 \mu \mathrm{g}$ of fentanyl (Sublimaze ${ }^{\oplus}$, Janssen Pharmaceutica, Piscataway NJ) with $8 \mathrm{ml}$ preservativefree normal saline (10 $\mathrm{ml}$ tolal volume) in a doubleblinded fashion. On arrival in the PAR (time 0), patients were connected via iv tubing to a PCA pump (Lifecare II ${ }^{\otimes}$, Abbolt Medical Products, Chicago, IL). The PCA pump was programmed to deliver meperidine $12.5 \mathrm{mg}$ every eight minutes with a maximum dose of $300 \mathrm{mg}$ over any four-hour interval.

The times between epidural fentanyl administration and arrival in the PAR and time of first PCA dose were recorded. A $10 \mathrm{~cm}$ visual analogue scale (VAS) for pain with $0=$ pain-free and $10=$ worst pain imaginable was used to measure the severity of pain at time 0 , and at 1,2 , $4,8,12$ and $24 \mathrm{hr}$ following arrival in the PAR. At these evaluation intervals similar VAS scale was used to assess satisfaction $(0=$ completely dissatisfied and $10=\mathrm{com}$ pletely satisfied). The total amount of $i v$-PCA meperidine administered at each interval in the first $24 \mathrm{hr}$ was determined, as were the number of times the patient self-administered meperidine (PCA bolus) and attempted to self-administer meperidine but was prevented by the lockout procedure (PCA attempt). Patients were observed for and questioned about side-effects including pruritus and nausea at each interval.

Sample size ( $n=40$ ) was determined based on difference between groups reported in similar patient populations.' Data were analyzed using Student's paired t-test, Chi-square analysis and Wilcoxon Rank Sum Test, with statistical significance accepted at $P \leq 0.05$. Data are reported as the mean $\pm S D$.

\section{Results}

There were no demographic differences between groups (Table). Three patients were eliminated from data analysis: one had inadequate regional anaesthesia requiring general anaesthesia, and two were withdrawn when they requested that the PCA be discontinued.

There were no differences between groups with respect to the duration of epidural anaesthesia, as assessed by resolution of motor blockade and sensory blockade 10 pinprick. There were no significant differences in the times between injection of the study drug and arrival in the PAR (time 0), $44.9+12.1 \mathrm{~min}$ in patients given epidural saline and $48.7+11.3 \mathrm{~min}$ in those given fentanyl.

There were no significant differences between groups with respect to time between epidural fentanyl administration and the first PCA dose. Patients given epidural fentanyl injected their first PCA dose after 150.0 \pm 20.2 min, compared with $146.7 \pm 50.8 \mathrm{~min}$ in patients given epidural saline. Pain scores at the time of first PCA narcotic administration and throughout the duration of the study were not different between groups (Figure I). Total meperidine dose administered at each interval and at $24 \mathrm{hr}$ was the same in both groups (Figure 2). The number of PCA boluses and PCA altempts were sinilar in both groups.

Side-effects in both groups were minimal, and differences between groups were statistically insignificant; nausea occurred in two of the patients given epidural saline, and in one patient who was given epidural fentanyl. Pruritus occurred in one individual in each group. There were no complaints or observations of excessive sedation or inadequate pain relief in any patient.

\section{Discussion}

In the present study, analgesia provided by epidurally administered fentanyl appeared to have negligible postoperative benefit and did not delay patient initiation of PCA or influence the total amount of patient self-administered meperidine. Epidural fentanyl did not appear to smooth

TABLE Paticnt characteristics

\begin{tabular}{|c|c|c|c|c|c|c|c|}
\hline & $N$ & $\begin{array}{l}\text { Height } \\
(\mathrm{ctm})\end{array}$ & $\begin{array}{l}\text { Weight } \\
(\mathrm{kg})\end{array}$ & Gravidity & Pariry & $\begin{array}{l}\text { Duration of } \\
\text { surgical } \\
\text { anaesthesia (min) }\end{array}$ & $\begin{array}{l}\text { Tolal dose of } \\
\text { lidocaine }(\mathrm{mI})\end{array}$ \\
\hline Fentanyl & 20 & $162.5 \pm 1.2$ & $78 \pm 12$ & $2 \pm 1$ & $1 \pm 0.7$ & $104.2 \pm 22.8$ & $23.0 \pm 4.6$ \\
\hline Saline & 17 & $162.6 \pm 1.6$ & $78 \pm 16$ & $2 \pm 1$ & $1 \pm 0.7$ & $99.5 \pm 13.8$ & $23.4 \pm 7.2$ \\
\hline
\end{tabular}




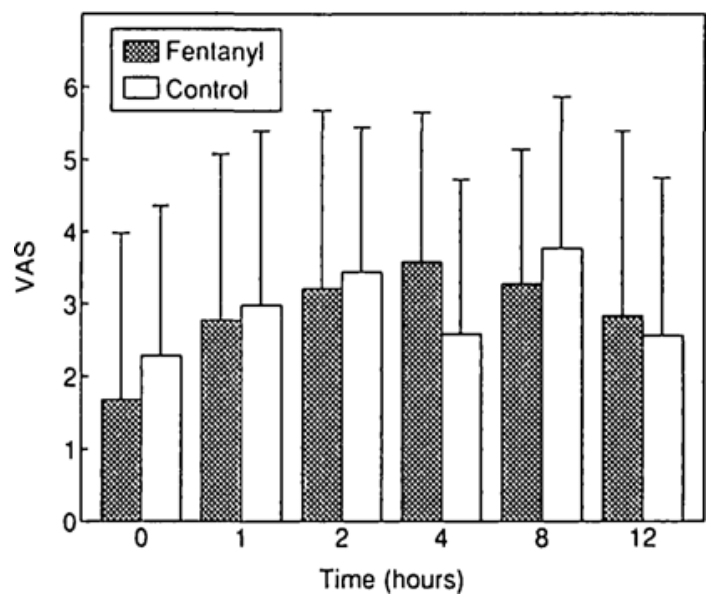

FIGURE I Visual analogue pain scores versus time following epidural injection of either $100 \mu \mathrm{g}$ fentanyl in $8 \mathrm{ml}$ normal saline ( $10 \mathrm{ml}$ total volunie) or $10 \mathrm{ml}$ normal saline.

transition to PCA therapy as pain scores in the fentanyl group throughout the early postoperative period were similar to those observed in the control group. However, with the small differences between groups seen in our patients, unlike in Naulty's cohort, ' we can state only that the difference in pain relief and difference in narcotic use between groups was much less than previously reported. A larger cohort needs to be examined to determine if indeed no difference exists between groups.

This apparent lack of efficacy may be in part related to the local anaesthetic employed and to our use of a protocol which permitted the patient, rather than a nurse or study evaluator, to determine analgesic effect and need for additional pain medication. By permitting patients to have ready access to pain medication using $i v$-PCA, we provided a more reliable means of assessing pain relief and analgesic requirements following epidural fentanyl. McQuay et al. ${ }^{7}$ found that effectiveness of pain relief provided by epidural opioid injection appeared to correlate inversely with PCA narcotic usage.

In an initial evaluation Naulty and co-workers ${ }^{1}$ reported that fentanyl $(75-100 \mu \mathrm{g}$ ) provided $4-5 \mathrm{hr}$ of complete analgesia and reduced 24-hr parenteral narcotic requirements in parturients recovering from Caesarean delivery performed using epidural anaesthesia $0.75 \%$ bupivacaine. It is probable that this potent long-acting agent, contributed to the effectiveness and duration of postoperative analgesia. Subsequent studies ${ }^{2.8 .9}$ using a local anaesthetic with a shorter duration of action have been unable to duplicate these findings and report at most only 1-2 hr of analgesia after Caesarean delivery. All these studies provided epidural anaesthesia with a local anaesthetic other than $0.75 \%$ bupivacaine. Malinow et al. ${ }^{2}$

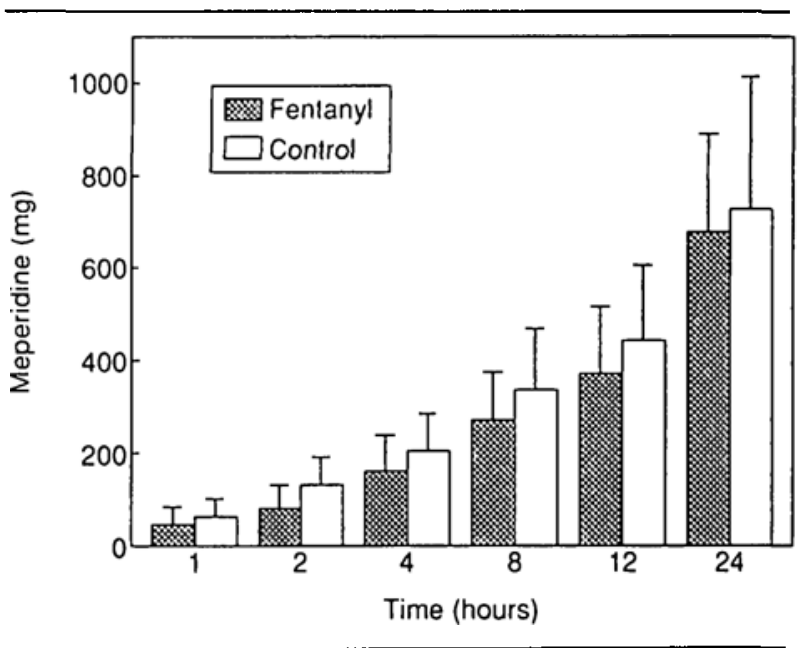

FIGURE 2 Total neperidine requirements at intervals following epidural injection of either $100 \mu \mathrm{g}$ fentanyl in $8 \mathrm{ml}$ normal saline ( $10 \mathrm{ml}$ lotal volume) or $10 \mathrm{ml}$ normal saline.

reported only 45 min of complete pain relief as measured by VAS in patients given epidural fentanyl following $0.5 \%$ bupivacaine or $2 \%$ lidocaine with epinephrine 1:200,000. Similarly, Madej et al. ${ }^{4}$ reported a $\mathrm{I}-2 \mathrm{hr}$ duration of epidural fentanyl analgesia following Caesarean delivery under epidural anaesthesia with $2 \%$ lidocaine with epinephrine $1: 200,000$.

The differences observed in the duration of postoperative analgesia in the above studies compared with the results using $0.75 \%$ bupivacaine may reflect residual but clinically imperceptible local anaesthetic activity that persists and potentiates fentanyl analgesia. ${ }^{10.11}$

Due to cardiovascular toxicity, bupivacaine $0.75 \%$ is now contraindicated for use in parturients and in most institutions has been replaced by lidocaine for epidural anaesthesia for Caesarean delivery. We conclude that a single bolus of epidural fentanyl does not provide any great advantage for postoperative pain relief in clinical obstetric anaesthesia to patients receiving intravenous PCA for postoperative analgesia.

\section{References}

1 Naulty JS, Datta S, Ostheimer GW, Jolmson MD.

Burger $G A$. Epidural fentanyl for post-cesarean delivery pain management. Anesthesiology 1965; 63: 694-8.

2 Malinow AM, Mokriski BLK, Wakefield ML et al. Choice of local anesthetic affects post-cesarean epidural fentanyl analgesia. Regional Anesthesia 1988; 13: 141-5.

3 Wang JK, Nanss LA, Thomas JE. Pain relief by intrathecally applied morphine in man. Anesthesiology 1979; 50: 149-51.

4 Madej TH, Sirunin L. Comparison of epidural fentanyl with sufentanil. Anaesthesia 1987; 42: 1156-61. 
5 Akerman B, Arweström BS, Posı C. Local anesthetics potentiate spinal morphine antinociception. Anesth Analg 1988; 67: 943-8.

6 Hanson AL, Matousek $M$. Epidural anesthesia for cesarean section. Acta Obstel Gynecol Scand 1984; 63: 135-40.

7 McQuay HJ, Bullingham RS, Evans PD, Lloyn JW, Moor $R A$. Demand analgesia to assess pain relief from epidural opiates. Lancet 1980; 768-9.

8 Preston PG, Rossen MA. Hughes $S$ et al. Epidural anesthesia with fentanyl and lidocaine for cesarean section: maternal effects and neonatal outcome. Anesthesiology 1988; 68: 938-43.

9 Mahesh KT, Heavmer JE. Post cesarean section analgesia requests are independent of when epidural fentanyl is given. Anesth Analg 1990; 70: S255.

10 Desprats R. Mannory J, Grandjean H, Amar B. Pontonner $G$, Lorewg $L$. Analgésie péridurale au cours du travail: étude comparative de l'association fentanyl-marcaïne et de la marcaïne seule. J Gyn Obst Biol Repr 1983; 901-5.

11 Hjortso NC, Lund C, Mogensen T, Bigler D, Kehlet $H$. Epidural morphine improves pain relief and maintains sensory analgesia during continuous epidural bupivacaine after abdominal surgery. Anesth Analg 1986; 65: 1033-6. 